\title{
Leaving Religion: Deconversion
}

\author{
Heinz Streib
}

Bielefeld University, Germany

Heinz.Streib@uni-bielefeld.de

Postal address: Bregenzer Str. 13, D-88131 Lindau, Germany

For print version see: $\underline{\text { https://doi.org/10.1016/j.copsyc.2020.09.007 }}$

\begin{abstract}
Religious change was an important theme in the psychology of religion from its beginning with a focus on conversion, but with the emergence of new religious movements and the recent growth of religious unaffiliation, religious exiting and deconversion received growing attention. This review evaluates recent progress in deconversion research by the inclusion of key psychological constructs, such as personality, values, attachment, prosociality, well-being, religious socialization and development, and by an engagement in longitudinal investigation. The Outlook calls for exploring more psychological constructs, focusing decisively on longitudinal assessment, accounting for cultural and religious differences, and keeping the balance and complementarity between nomothetic and idiothetic approaches in order to account for the varieties of biographical changes that are denoted by 'deconversion.'
\end{abstract}

\section{Keywords}

Deconversion; leaving religion; disaffiliation; religious nones; atheists; spirituality; religious development 


\section{Introduction}

Leaving religion is used here as synonymous with deconversion. This is a reminder, especially when we focus our review mainly on quantitative studies, that it is a process of biographical change that parallels conversion and involves multiple dimensions [1-3], which may include, finally, the termination of membership in a religious community, but it may also involve the loss of religious experience, intellectual doubt or denial regarding religious beliefs, criticisms of the morality and the values of the religious community, and emotional suffering or crises $[2,4,5]$.

While psychologists of religion, from the beginning of the discipline, focused their attention on conversion [6,49], investigation on deconversion is relatively young, and is growing with the increasing awareness of religious plurality, particularly in American and European societies-a plurality in which new religious movements (NRM) have emerged. Thus, the majority of early-and mostly interview-based, retrospective-studies on deconversion have focused upon exiters from NRMs [5,7-10] with special attention to their search for freedom and autonomy, but also to their emotional suffering, crises, and wellbeing after deconversion. The study of deconversion from NRMs has continued to the present on a smaller scale, while deconversion research generally expanded its focus to include fundamentalist and evangelical Christians [11,12], Mormons [13,14], Orthodox Jews $\left[15^{* *}, 16\right]$, Muslims [17-19], and deconversions from a broad range of religious traditions $[5,20]$.

A new perspective emerged with the increasing research interest in the growing portions of individuals with no religious affiliation (religious "nones"), atheists, and agnostics [21,22]-survey data for 2018 document, for example, ca. 25\% religious nones in the USA [23], ca. 40\% in Germany. Thus, "with each generation irreligious socialization will increasingly fuel the growth among religious nones more so than disaffiliation" [24]. Now, the growing number of life-long irreligious and life-long atheists invites comparison with the deconverts who, while raised religiously, later adopt an irreligious or atheist identity. This constitutes a most recent line of research [25-27] that is based on, and provides evidence for, the assumption that people, who have stepped out from their original family's religious community or belief in God into an irreligious or atheist identity, take a middle position between life-long non-affiliates or atheists, on the one side, and life-long religious people, on the other side. This middle position is observable on certain psychological characteristics, as will be detailed below.

Deconversion research is still in the process of identifying the most influential factors that characterize deconversion. Recent research has investigated key constructs in psychology to portray the characteristics of deconverts and the variety of deconversion processes; these include: personality traits, values, attachment, well-being, prejudice, self-rated spirituality, and religious 
development. Of these constructs some can be tentatively regarded potential predictors, while others, to be on the safe side, should be regarded characteristics, because only longitudinal investigation may lead to greater confidence regarding their potential function as predictors or outcomes.

\section{Potential Predictors of Deconversion}

\subsection{Personality}

From the five factors of personality [28], especially emotional stability (neuroticism, reversed), openness to experience, [p. 140] and agreeableness appear to be related to deconversion-with only partially concurrent results, however. Considerable agreement is presented for emotional stability: In one study, emotional stability was lower for German deconverts, compared to their former peers in the religious communities [5], which is corroborated in longitudinal analysis [29**]; however, US deconverts in the same study had slightly higher emotional stability. A study in Belgium concludes that being emotionally unstable may be among the characteristics of deconverts [ $26^{* *}$. Lower scores on emotional stability longitudinally predicted disaffiliation also in a Chinese sample [30**]. But in another longitudinal study using nine waves of the New Zealand Attitudes and Values Study (NZAVS) for estimating piece-wise latent growth models [31*], emotional stability was not observed as a predictor of deconversion.

There are less coherent results for openness to experience: One study found that openness to experience was one standard deviation higher in deconverts in both the USA and Germany, compared to their former religious peers [5], and openness to experience predicted deconversion tentatively [5], while another study [26**] found rather marginal effects of openness to experience in regard to deconversion. Finally, in the longitudinal New Zealand study [31*], only lower scores for agreeableness were a significant predictor for deconversion, but the other big five factors were not.

\subsection{Values}

Schwartz's [32] Portrait Values Questionnaire (PVQ) has been included in studies about deconverts $\left[26^{* *}, 30^{* *}, 33\right]$. Using the PVQ in longitudinal research with Chinese deconverts evidenced that "faith exit is predicted by the values of self-direction, stimulation, hedonism, achievement, and power" $\left[30^{* *}, 33\right]$. Correspondingly, the study in Belgium reveals that deconverts have lower scores on conservation values (security, conformity, tradition), but may maintain "a spiritual emphasis on prioritizing quality in interpersonal relationships over attachment to 'materialistic' values, i.e., hedonism and power" [26**]. 


\subsection{Attachment}

The first systematic study focusing on attachment [34] for better understanding deconversion [15**] concludes that "the main themes underlying religious conversion and their association with attachment orientations also apply to apostasy." For both (re-)converts to and deconverts from Orthodox Judaism, two developmental pathways were relevant: Emotional compensation is the path for those higher in attachment anxiety, and exploration is the path for those lower in attachment anxiety and avoidance. Interestingly, the results suggest that those on the compensation pathway engage in rather sudden and emotionally turbulent religious change, sometimes very critical towards their highly religious family, while the exploration pathway is a rather gradual of seeking out new and alternative identities.

\subsection{Family and Religious Socialization}

Using longitudinal data from the US National Study of Youth and Religion, one study [35*] found that experiencing a rite of passage (such as bar/bat mitzvah, confirmation) before the teenage years predicts a $30 \%$ lower chance for religious disaffiliation in early adulthood. Another longitudinal study, based on data from US adolescents and their parents at two times of measurement $2 \frac{1}{2}$ years apart [36], indicates that adolescents who became religious and had joined the church of their parents at Time 2 were at Time 1 higher in social competence than deconverting adolescents, while adolescents who moved away from their parent's religion were lower in parent communication.

\section{Further Characteristics of Deconverts}

\subsection{Prosocial Behavior and Interreligious Prejudice}

Disaffiliates are more prosocial compared to life-long non-affiliates in prosocial behavior such as volunteering in charitable work [ $\left.25^{* *}\right]$, which indicates what the authors interpret as a "residue effect" from their former religiosity. This residue effect was evidenced particularly in their third study using waves 1-9 of the NZAVS. Comparable findings are reported $\left[27^{*}\right]$ for people in four nations who abandoned their belief in God: Deconverted atheists, compared to life-long atheists, are higher in self-rated religiosity and spirituality, and lower in inter-religious prejudice toward different religious groups such as the majority religion in their country, minority religions, and Islam in particular.

\subsection{Well-being}

Compared with stable members in religious organizations, deconverts in Germany had lower scores on the Psychological Well-Being and Growth Scale [37] in environmental mastery, positive relations with others, purpose in life, and self-acceptance, which was interpreted as "signs of a loss or a crisis" 
[5]-which corresponds to their lower scores on emotional stability, which has been noted above; the US deconverts, however, had slightly higher scores on well-being. Longitudinal investigation of the German deconverts [29**] adds to this finding that lower scores on purpose in life and selfacceptance appear to be associated with deconversions in the more recent years, but may improve in a timespan of ten years. The evaluation of in-depth interviews with 24 exiters from fundamentalism in the USA [12] indicates that well-being enhanced with deconversion; and the author concludes that freedom from religious conformity, new secular relationships with mutual emotional exchanges, an enhanced sense of autonomy, and personal freedom may have contributed to their greater well-being.

[p. 141] These contradictory results are reflected in the study with Chinese deconverts $\left[30^{* *}\right]$ :

"changes in psychological well-being are not identical for all faith exiters," but "for some, leaving the religion is psychologically beneficial; for others, leaving the religion has just the opposite consequence." A possible explanation is offered in the study with deconverts and reconverts to Orthodox Judaism: Using the Mental Health Inventory [38], the results indicate that less favorable well-being is associated with attachment anxiety and this association is stronger in deconversions on the compensation pathway [15**].

3.3 Spiritual Self-identification

Self-identified spirituality appears to be associated with deconversion. Deconverts show a higher preference for "more spiritual than religious" self-identification: Deconverts from the USA and Germany self-identify as "more spiritual than religious" with double the frequency than people who continued their affiliation to their religious community [5]. This pattern emerged also from the data at Time $2\left[29^{* *}\right]$. Also, the study with deconverts in Belgium [26**] included attention to spiritual self-identification, but revealed much lower differences between traditionalists and deconverts: $60.2 \%$ deconverts self-identify as " spiritual rather than religious," which is slightly higher than the socialized non-believers (56.1\%) and socialized believers (47.6\%), but lower than the converts (65.6\%).

\subsection{Religious Development}

Progress in religious development is associated with deconversion, and religious development may be a potential outcome of deconversion. A perspective on religious development can be based on a cognitive-structural model [41] that assumes a set of hierarchically ordered distinct styles (previously called stages), which are assumed to change and develop over the life-span. Thus, based on a the model of religious styles [39] and religious types [40], which are assessed with the faith development interview [41], deconverts at Time 1 were assigned the Predominantly Individuative-Reflective Type 
in much higher numbers $(41.9 \%)$ than the traditionalists (16.2\%), i.e., respondents who remained affiliated with their religious tradition. Correspondingly, the Predominantly Conventional Type was assigned for deconverts (40.9\%) less than for traditionists (59.8\%) $[5,29 * *]$. This pattern was fairly stable for Time 2 of measurement [29**]. Since individuative and autonomous reflection, which is the characteristic of the Predominantly Individuative-Reflective Type, is regarded more advanced and "higher" compared to the Predominantly Conventional Type, who desires to preserve convention, tradition and harmony at the cost of individuative reflection, these results indicate that deconverts are more advanced in religious development, compared to their former fellow-believers.

\section{A Variety of Biographical Trajectories of Deconverts}

Are deconverts always secular exiters? It may seem that way under the impression of the current strong research interest in the question, how people become religious nones $\left[24,25^{* *}, 27^{* *}, 42,43\right]$ or how fundamentalist Christians become atheists [44]. However, many studies document that deconversion trajectories and their psychological developments are a variety and may differ considerably $\left[2,11,15^{* *}, 30^{* *}\right]$; therefore, "any theory asserting that all faith exiters change in the same way should be viewed with suspicion" [30**]. This variety includes also the change to a "spiritual rather than religious" identity, which may involve an exit into private spiritual practice without any interest in organized religion [45]. But still another possibility is, perhaps years later, a new affiliation of the deconvert with another religious tradition. Finally, the variety also includes the option of multiple deconversions and conversions. The existence and the profile of the so-called "accumulative heretic" is known at least for two decades [46] and is further documented as the "lifelong quest-late revisions" type [5]. The variety of deconversion trajectories is ideally based on narrative analysis and on an integration of psychodynamic perspectives [47].

Research in the psychology of religion is beginning to account for the variety of deconversion trajectories, but typologies are rather tentative. Based on narrative interviews and faith development interviews with 99 deconverts in the USA and Germany, a typology of biographical deconversion trajectories has been developed [5] that consists of four types: a) search for autonomy, b) debarred from paradise, c) finding a new frame of reference, and d) life-long quests-late revisions. From the study of deconverts and re-converts in Israel [15**], a typology emerged, which the authors tentatively link to these [5] four types of deconversion trajectories: the barred from paradise type may relate to the compensation path with higher attachment-anxiety, while the pursuit of autonomy and the life-long quest type may relate to the exploration path with higher secure attachment, and finally, the finding a new frame of reference type may correspond to the socialization path. 


\section{Conclusions and Recommendations for Future Research}

Twenty years ago, it was concluded for conversion research that most studies are retrospective, cross-sectional, and constitute no systematic program of research [48]. This was largely true also for deconversion research ten years ago, and in 2013 , deconversion research was regarded to be still in its infancy [49]; but there is progress in the more recent years: Besides our own current study, five longitudinal studies could be identified $\left[25^{* *}, 30^{* *}, 31^{*}, 35^{*}, 36\right]$ for this review, but still most other studies are based on cross-sectional data. More longitudinal studies [p.142] are needed, not only to determine the direction of effects and identify predictors and outcomes with greater confidence, but because deconversion is a dynamic biographical process that eventually has long-term, slowlychanging predictors and outcomes.

Further, considerable progress has been made with the inclusion of psychological key constructs such as personality, values, or well-being-and of special importance: attachment theory-into deconversion research. Where results are contradictory, future research is needed. But also, there may be other constructs still waiting to be explored, such as need for cognition, tolerance of ambiguity, or mysticism. This list is by no means exhaustive, of course, but it may point to "dooropeners" for a more comprehensive investigation of how deconversion is related to, and perhaps motivated by, (changes in) cognition, such as the appreciation of engaging in thinking and exploring new and eventually ambiguous ideas, or (changes in) experience, such as mystical experiences that are associated with the preference for a "more spiritual" self-identification [50] and with a search for own's own spiritual path. There is still some way to go before deconversion research may step out of infancy and arrive at a coherent and systematic program of research.

For a coherent approach and also for the unambiguous comparison of studies, there is need for discussing and clarifying the basic concepts used for 'leaving religion.' Some studies have used the criterion of (dis-)affiliation and talk about "nones" (and "dones") [25**]; others used (rejection of) belief in God and talk about "nonbelievers" or "atheists," etc.; still others rely on self-identification as "religious," self-reports of church going, or assess the participants' (centrality of) religiosity with a scale. The use of 'deconversion' as a label is widely adopted nevertheless; but the multi-dimensional and processual character of deconversion needs to be taken into account more decisively.

In the more recent contributions to deconversion research, the cultural diversity is impressive when samples were collected in China, New Zealand, Israel, Belgium, Germany, the USA, and many other countries (some studies use multi-nation samples). But eventually, cultural differences, or more specifically: differences between the various religious actors within and across these religious fields, may generate a variety of different versions of deconversion. The differences 
between German and US deconverts in emotional stability and well-being that were documented in one study [5] and noted above are no more than a beginning.

This review has focused in most part on the quantitative, nomothetic approaches to deconversion. In concluding, it should however be emphasized that qualitative studies with ideographic (intra-individual difference) and idiothetic (inter-individual difference) approaches [47], especially when both are longitudinal, could take further and complement the nomothetic results with the analysis of individual biographies-an ideal way to enrich and deepen the account for the variety of deconversion trajectories.

\section{Acknowledgements}

The author thanks Barbara Keller and Zhuo Chen for helpful comments on earlier drafts of this paper, and Anika Steppacher, Ramona Bullik, and Florian Schmidt for their help in searching the literature. This work has been produced as part of a project that was funded by the John Templeton Foundation (Grant 60806).

\section{Conflict of interest statement}

Nothing to declare.

\section{References}

1. Paloutzian RF, Murken S, Streib H, Namini S: Conversion, Deconversion, and Transformation: A Multilevel Interdisciplinary View. In Handbook of the Psychology of Religion and Spirituality, 2nd Ed. Edited by Paloutzian RF, Park CL: The Guilford Press; 2013:399-421.

2. Streib H, Keller B: The Variety of Deconversion Experiences: Contours of a Concept in Respect to Empirical Research. Archive for the Psychology of Religion 2004, 26:181-200, https://doi.org/10.1163/0084672053598030

3. Streib H: Deconversion. In Oxford Handbook on Religious Conversion. Edited by Rambo LR, Farhadian CE: Oxford University Press; 2014:271-296. https://doi.org/10.1093/oxfordhb/9780195338522.013.012

4. Barbour JD: Versions of Deconversion. Autobiography and the Loss of Faith. Charlottesville: Univ.Press of Virginia; 1994.

5. Streib H, Hood RW, Keller B, Csöff R-M, Silver C: Deconversion. Qualitative and Quantitative Results from Cross-Cultural Research in Germany and the United States of America. Göttingen: Vandenhoeck \& Ruprecht; 2009.

6. Hood RW, Hill PC, Spilka B: The Psychology of Religion: An Empirical Approach, 5th Ed. New York: Guilford Press; 2018.

7. Wright SA: Leaving Cults: The Dynamics of Defection. Washington: Society for the Scientific Study of Religion; 1987.

8. Wright SA: Disengagement and Apostasy in New Religious Movements. In The Oxford Handbook of Religious Conversion. Edited by Rambo L, Farhadian CE: Oxford Univ. Press; 2014:706-735.

9. Bromley DG (Ed): Falling from the Faith Newbury Park: Sage; 1988. 
10. Lewis JR, Tøllefsen IB (Ed): The Oxford Handbook of New Religious Movements, 2nd Ed. New York, NY: Oxford University Press; 2016.

11. Fazzino LL: Leaving the Church Behind: Applying a Deconversion Perspective to Evangelical Exit Narratives. Journal of Contemporary Religion 2014, 29:249-266, https://doi.org/10.1080/13537903.2014.903664

12. Nica A: Exiters of Religious Fundamentalism: Reconstruction of Social Support and Relationships Related to Well-Being. Mental Health, Religion \& Culture 2019, 22:543-556, https://doi.org/10.1080/13674676.2019.1636015

13. Ormsbee JT: 'Like a Cord Snapping': Toward a Grounded Theory of How Devout Mormons Leave the Lds Church. Critical Research on Religion 2020, https://doi.org/10.1177/2050303220924096

14. McGraw JS, Peer SO, Draper MR: Reactionary Deconversion from Mormonism: Polarization of Ideological and Behavioral Religiosity among Active and Former Mormons. Review of Religious Research 2018, 60:535-553, https://doi.org/10.1007/s13644-018-0343-8

15**. Greenwald Y, Mikulincer M, Granqvist P, Shaver PR: Apostasy and Conversion: Attachment Orientations and Individual Differences in the Process of Religious Change. Psychology of Religion and Spirituality 2018, https://doi.org/10.1037/rel0000239

This study demonstrates the benefits of including attachment theory in the study of deconversion. Attachment-related variations (attachment anxiety; avoidance) and their relation to religious change themes (compensation, exploration, socialization) open perspectives on individual differences: attachment anxiety is associated with emotional compensation, and compensation themes are associated with lower well-being at present and a heightened link between attachment anxiety and distress, while attachment security is less related to compensation themes, but rather open for the exploration of new ideas.

16. Engelman J, Milstein G, Schonfeld IS, Grubbs JB: Leaving a Covenantal Religion: Orthodox Jewish Disaffiliation from an Immigration Psychology Perspective. Mental Health Religion \& Culture 2020, https://doi.org/10.1080/13674676.2020.1744547

17. Cottee S: The Apostates: When Muslims Leave Islam. London: Hurst \& Co; 2015.

18. van Nieuwkerk K: Moving in and out of Islam. Austin, TX: University of Texas Press; 2018.

19. Vliek M: 'It's Not Just About Faith': Narratives of Transformation When Moving out of Islam in the Netherlands and Britain. Islam and Christian-Muslim Relations 2019, 30:323-344, https://doi.org/10.1080/09596410.2019.1628459

20. Gooren H: Religious Conversion and Disaffiliation: Tracing Patterns of Change in Faith Practices. New York: Palgrave Macmillan; 2010.

21. Streib H, Klein C: Atheists, Agnostics, and Apostates. In APA Handbook of Psychology, Religion, and Spirituality, Volume 1: Context, Theory, Research. Edited by Pargament KI, Exline JJ, Jones JW: American Psychological Association; 2013:713-728. https://doi.org/10.1037/14045-040

22. Keller B, Bullik R, Klein C, Swanson SB: Profiling Atheist World Views in Different Cultural Contexts: Developmental Trajectories and Accounts. Psychology of Religion and Spirituality 2018, 10:229-243, https://doi.org/doi:10.1037/rel0000212

23. Pew_Research_Center: In U.S., Decline of Christianity Continues at Rapid Pace. An Update on America's Changing Religious Landscape. Washington: Pew Research Center; 2019.

24. Thiessen J, Wilkins-Laflamme S: Becoming a Religious None: Irreligious Socialization and Disaffiliation. Journal for the Scientific Study of Religion 2017, 56:64-82,

https://doi.org/10.1111/issr.12319

25**. Van Tongeren DR, DeWall CN, Chen Z, Sibley CG, Bulbilia J: Religious Residue: Cross-Cultural Evidence That Religious Psychology and Behavior Persist Following Deidentification. Journal of Personality and Social Psychology 2020, https://doi.org/10.1037/pspp0000288 This paper presents three studies using nationally representative samples of religious Western culture (United States), secular Western (Netherlands, New Zealand) and Eastern (Hong Kong) cultures. Results showed evidence of what the authors call a religious residue effect. While Study $1(N=3,071)$ offered initial cross-cultural evidence, which was extended in a preregistered replication study that also included measures of charitable contribution 
(Study 2; $N=1,626$ ), it is especially Study 3 ( $N=31,464$ from the New Zealand Attitudes and Values Study) to demonstrate that individuals who deidentified were still relatively likely to engage in prosocial behavior (e.g., volunteering) after leaving religion.

26**. Saroglou V, Karim M, Day JM: Personality and Values of Deconverts: A Function of Current Nonbelief or Prior Religious Socialisation? Mental Health, Religion \& Culture 2020:1-14, https://doi.org/10.1080/13674676.2020.1737922

This study is important as it relates deconversion with personalty (big five) and values (Schwartz). Results based on data from 404 adults in Belgium indicated that deconverts were more similar to socialised nonbelievers regarding neuroticism and decreased conservative values. But they were midway, approaching socialised believers regarding increased spirituality and benevolence and, partly due to age differences, decreased power and hedonism. Further, the deconverts' abandon of faith may denote search for autonomy, whereas religious education may contribute to their endorsement of self-transcendence over materialistic values.

27*. Pauha T, Renvik TA, Eskelinen V, Jettern J, vanderNoll J, Kunst JR, Rohmann A, Jasinskaja-Lahti I: The Attitudes of Deconverted and Lifelong Atheists Towards Religious Groups: The Role of Religious and Spiritual Identity. International Journal for the Psychology of Religion 2020, https://doi.org/10.1080/10508619.2020.1774206

This study compared life-long atheists with deconverted atheists in four nations (Australia, Finland, Germany, and Norway) to investigate the relationships between deconversion, religious identity, spiritual identity, and interreligious attitudes. Results demonstrate that higher religious or spiritual identity among deconverts is associated with more positive attitudes towards different religious groups (national religious majority, religious minorities in general, and Muslims specifically).

28. McCrae RR, Costa PT: Personality Trait Structure as a Human Universal. American Psychologist 1997, 52:509-516

29**. Streib H, Keller B: Quantitative Portrayal of the Re-Interviewees from the Deconversion Study. In Deconversion Revisited. Longitudinal Biographical Analyses Ten Years Later. Edited by Streib H, Keller B, Bullik R, Silver CF, Hood RW; pre-print.

https://doi.org/10.13140/RG.2.2.14932.83844

This chapter will be included in the book Deconversion Revisited. Longitudinal Biographical Analyses Ten Years Later, which is supposed to be published in fall of 2020. The chapter presents quantitative analyses of participants in the Deconversion Study (published 2009) who were re-interviewed recently. Results compare deconverts with traditionalist (that is, people who stayed in their religious group and did not deceonvert) and document continuity and change in: religious types, self-rated spirituality, the Religious Schema Scale, personality (NEO-FFI), and well-being (Ryff-Scale). Especially noteworthy are lower scores of deconverts on emotional stability, agreeableness, purpose in life, and self-acceptance in longitudinal perspective.

30**. Hui CH, Cheung S-H, Lam J, Lau EYY, Cheung S-F, Yuliawati L: Psychological Changes During Faith Exit: A Three-Year Prospective Study. Psychology of Religion and Spirituality 2018, 10:103-118, https://doi.org/10.1037/rel0000157

This longitudinal study explored psychological changes in deconversion. It identified characteristics of Christians in China who deconverted within a 3-year time frame. Results indicate that about half of the deconverts initially experience an improvement in psychological symptoms, and the other half a deterioration. Low emotional stability predicted deconversion, while the other Big Five factors did not. The findings strongly suggest that changes in beliefs and values might have begun long before the actual faith exit, whereas personality change, if any, might take a long time after the transition.

31*. Stronge S, Bulbulia J, Davis DE, Sibley CG: Religion and the Development of Character: Personality Changes before and after Religious Conversion and Deconversion. Social Psychological and Personality Science 2020, Article 1948550620942381

https://doi.org/10.1177/1948550620942381 
This study used a representative national sample of New Zealand adults over 9 years (2009$2017, \mathrm{~N}=31,604$ ) and piecewise latent growth models to assess longitudinal change in big five personality and honesty-humility before and after conversion to or deconversion from Christianity ( $N=540$ converts, $N=886$ deconverts). The researcher did observe no personality changes before conversion or after deconversion. Result regarding deconverts demonstrate increases in honesty-humility and decreases in agreeableness preceding deconversion.

32. Bilsky W, Janik M, Schwartz SH: The Structural Organization of Human Values-Evidence from Three Rounds of the European Social Survey (ESS). Journal of Cross-Cultural Psychology 2011, 42:759-776, https://doi.org/10.1177/0022022110362757

33. Hui CH, Lau EYY, Lam J, Cheung SF, Lau WWF: Psychological Predictors of Chinese Christians' Church Attendance and Religious Steadfastness: A Three-Wave Prospective Study. Psychology of Religion and Spirituality 2015, 7:250-264, https://doi.org/10.1037/a0039216

34. Granqvist P: Attachment in Religion and Spirituality. A Wider View New York; London: The Guilford Press; 2020.

35*. Perry SL, Longest KC: Examining the Impact of Religious Initiation Rites on Religiosity and Disaffiliation over Time. Journal for the Scientific Study of Religion 2019, https://doi.org/10.1111/issr.12632

Using longitudinal data from the US National Study of Youth and Religion, this study examined whether experiencing a religious rite of passage during or before one's teenage years predicts the religious change in young adulthood. Results demonstrate that those who experienced a religious rite of passage such as baptism, bar/bat mitzvah, confirmation were $30 \%$ less likely to disaffiliate between data collection points. The authors conclude that the experience of rites of passage matter primarily as durable markers of social identity, binding adherents to their faith community, if only nominally.

36. Longo GS, Kim-Spoon J: What Drives Apostates and Converters? The Social and Familial Antecedents of Religious Change among Adolescents. Psychology of Religion and Spirituality 2014, 6:284-291, https://doi.org/10.1037/a0037651

37. Ryff CD: Happiness Is Everything, or Is It? Explorations on the Meaning of Psychological WellBeing. Journal of Personality and Social Psychology 1989, 57:1069-1081, https://doi.org/10.1037/0022-3514.57.6.1069

38. Florian V, Drory Y: Mental Health Inventory (MHI) - Psychometric Properties and Normative Data in the Israeli Population. Psychologia: Israel Journal of Psychology 1990, 2:26-35,

39. Streib H: Faith Development Theory Revisited: The Religious Styles Perspective. International Journal for the Psychology of Religion 2001, 11:143-158, https://doi.org/10.1207/S15327582IJPR1103 02

40. Streib H, Chen ZJ, Hood RW: Categorizing People by Their Preference for Religious Styles: Four Types Derived from Evaluation of Faith Development Interviews. International Journal for the Psychology of Religion 2020, 30:112-127, https://doi.org/10.1080/10508619.2019.1664213

41. Fowler JW: Stages of Faith. The Psychology of Human Development and the Quest for Meaning. San Francisco: Harper\&Row; 1981.

42. Starr C, Waldo K, Kauffman M: Digital Irreligion: Christian Deconversion in an Online Community. Journal for the Scientific Study of Religion 2019, 58:494-512, https://doi.org/10.1111/issr.12599

43. Perez S, Vallieres F: How Do Religious People Become Atheists? Applying a Grounded Theory Approach to Propose a Model of Deconversion. Secularism \& Nonreligion 2019, 8:1-14, https://doi.org/10.5334/snr.108

44. Lee KA, Gubi PM: Breaking up with Jesus: A Phenomenological Exploration of the Experience of Deconversion from an Evangelical Christian Faith to Atheism. Mental Health Religion \& Culture 2019, 22:171-184, https://doi.org/10.1080/13674676.2019.1623767.

45. Streib H, Hood RW, Keller B: Deconversion and "Spirituality:" - Migrations in the Religious Field. In Semantics and Psychology of "Spirituality". A Cross-Cultural Analysis. Edited by Streib H, 
Hood RW: Springer International Publishing Switzerland; 2016:19-26.

https://doi.org/10.1007/978-3-319-21245-6 2

46. Streib H: Biographies in Christian Fundamentalist Milieus and Organizations (Part of the Research Project on "Drop-Outs, Converts and Believers: Contrasting Biographical Analyses of Why Individuals Join, Have a Career and Stay in, or Leave Religious/Ideological Contexts or Groups"). In Final Report of the Enquête Commission on 'So-Called Sects and Psychogroups'. New Religious and Ideological Communities and Psychogroups in the Federal Republic of Germany. Edited by Deutscher Bundestag, Referat Öffentlichkeitsarbeit: Deutscher Bundestag; 1999:402-414.

47. Keller B: Taking Psychoanalytic and Psychometric Perspectives toward a Binocular Vision of Religion. Leiden: Brill; 2020.

48. Paloutzian RF, Rambo LR, Richardson JT: Religious Conversion and Personality Change. Journal of Personality 1999, 67:1047-1080, https://doi.org/10.1111/1467-6494.00082

49. Hood RW, Chen Z: Conversion and Deconversion. In The Oxford Handbook of Atheism. Edited by Bullivant S, Ruse M: Oxford Univ. Press; 2013.

https://doi.org/0.1093/oxfordhb/9780199644650.013.024

50. Streib H, Klein C, Keller B, Hood RW: The Mysticism Scale as Measure for Subjective Spirituality: New Results with Hood's M-Scale and the Development of a Short Form. In Assessing Spirituality and Religion in a Diversified World. Edited by Ai AL, Harris KA, Wink P: Springer International Publishing Switzerland; 2020. https://doi.org/10.1007/978-3-030-52140-0 